\title{
Pathology of atrial fibrillation in man
}

\author{
M. J. Davies and Ariela Pomerance \\ From the Departments of Pathology, St. George's Hospital Medical School; \\ and The Central Middlesex Hospital, London
}

Quantitative studies on the sinoatrial $(S A)$ node and internodal tracts in 100 hearts from patients coming to necropsy with atrial fibrillation have been carried out. In patients with atrial fibrillation developing only in the last two weeks of life, pulmonary emboli and acute pericarditis were common precipitating factors. Atrial dilatation was common but the $S A$ node and internodal tracts were within normal limits. In contrast patients with long-term atrial fibrillation showed combinations of nodal artery stenosis, muscle loss in the $S A$ node or internodal tracts, and atrial dilatation. The pathological conditions found most commonly were chronic rheumatic valve disease, ischaemic heart disease, hypertension, and cor pulmonale. Atrial fibrillation in some aged patients was associated with loss of muscle fibres in the SA node without any clear pathological cause.

The sinoatrial (SA) node is now universally accepted as the site of initiation of the impulse for cardiac contraction; it is also well established that specialized myogenic fibres are responsible for its inherent rhythm (Hoffman and Cranefield, 1960). The impulse passes to the atrioventricular node via internodal tracts within the atria (James, I96I, I963) and, while in man these tracts do not have specific histological features, there is ample physiological proof of their existence (Vassalle et al., I964).

Great emphasis has always been placed on the pathophysiological basis of atrial fibrillation, both in man and animals. The morphological changes which may predispose to or accompany this arrhythmia have received considerably less attention. Clinical studies in man have shown conditions such as rheumatic valve disease to be strongly associated with atrial fibrillation (Stock, 1970). Old age seems both to predispose to atrial fibrillation (Taran and Szilagyi, 1958) and to mitigate against DC conversion (Waris, Kreus, and Salokannel, 1971).

Though our knowledge of the pathology of atrial fibrillation is far from complete, valuable work has been carried out by Hudson (1965) who suggested that damage to the SA node was one factor. Other features described in this arrhythmia include damage to internodal pathways (James, 1962), atrial dilatation (Laas, 1962), and occlusion of the nodal artery

Received 28 July 197 I.
(Lippestad and Marton, 1967). It is uncertain, however, whether each of these lesions can cause arrhythmia acting singly, or in combination or, indeed, if they are invariably present in atrial fibrillation. It is also probable that in some transitory episodes of atrial fibrillation, as in digitalis therapy, purely physiological mechanisms are acting without structural damage.

\section{Materials and methods}

Hearts were taken from Ioo patients with atrial fibrillation coming to necropsy at St. George's Hospital and The Central Middlesex Hospital, London. These patients represent a consecutive series over a one-year period. All the patients had an electrocardiogram recording atrial fibrillation during the last two weeks of life, and cases were only included when clinical data gave information on the time of onset and duration of the arrhythmia. Cases were divided into short term when the arrhythmia had been present for under two weeks before death, and long term, with atrial fibrillation over one month in duration. Of the 100 patients, 44 were women; the ages of the patients in the series overall ranged from 46 to $9 \mathrm{I}$ years at death. The duration of atrial fibrillation ranged from I month to Io years in the long-term group.

Hearts were fixed in 4 per cent formaldehyde in saline after lightly packing the atria with cotton wool. Subsequently atrial volume was calculated by weighing atrial wax casts. The majority of hearts were subjected to postmortem coronary angiography using a barium gelatin suspension injected at $80 \mathrm{mmHg}$ pressure.

The SA node and internodal tracts were examined and quantitatively assessed for the amount 
of muscle, fibrous tissue, and fat present by point counting (Dunnill, 1962), using slides stained by the picro-Mallory stain. This technique has previously been described (Davies and Pomerance, 1972). Using a combination of serial blocks of the main coronary arteries, coronary angiograms, and serial blocks of the nodal artery within the itria, assessment was made of the presence of any significant impairment of nodal blood supply. Stenosis was judged to be present if there was stenosis greater than 75 per cent in the main coronary artery proximal to the origin of the nodal artery, or histological evidence of recanalization in the main coronary artery proximal to the origin lof the nodal artery, or histological evidence of recanalization in the nodal artery itself, and, of course, any combination of these three.

The nodal artery lumen, media, and intima were measured in arbitrary units using a graduated eyepiece. Within the node, the artery is seen in histological sections in direct cross-section and can be measured in one plane.

Control data on patients with sinus rhythm flave already been published (Davies and Pomerance, 1972); these data were derived by methods identical to those used in the present study. Control data showed that there were obvious changes in the SA node and internodal tracts with age. These consist of some loss of muscle fibres and a degree of atrial dilatation.

\section{Results}

Short-term fibrillation The main pathological conditions found in the 26 patients with short-term atrial fibrillation are shown in Table I. Right atrial volume was considerably increased in most (Fig. I) and was invaribly high in cases associated with pulmonary embolism; left atrial volume (Fig. 2) was less consistently raised. Study of the SA node revealed that in the majority there was no muscle loss (Fig. 3) and the internodal tracts were normal (Fig. 4). In cases with acute pericarditis the inflammatory reaction lay immediately adjacent to, but did not actually involve the node. In addition to the 2 patients with pericarditis complicating acute myocardial infarction, 4 other patients with acute

TABLE I Essential pathology in short-term $-<2$ weeks) atrial fibrillation

\begin{tabular}{|c|c|c|}
\hline- & 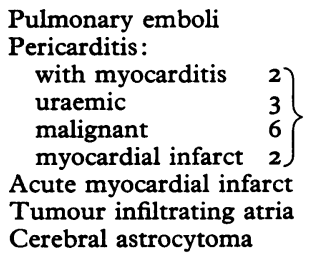 & $\begin{array}{l}4 \\
\text { I } \\
\text { I }\end{array}$ \\
\hline$\checkmark$ & Total & 26 \\
\hline
\end{tabular}

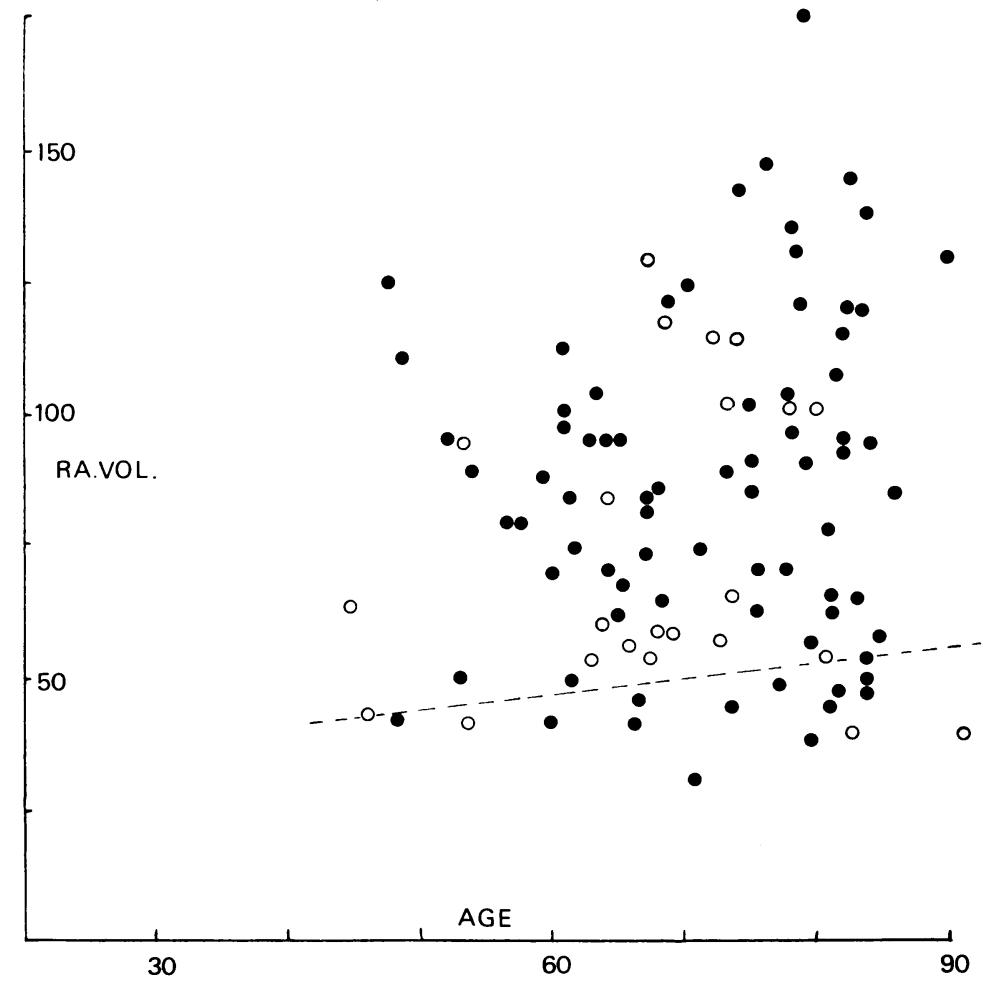

FIG. I The right atrial volume $(\mathrm{ml})$ of 74 cases with long-term fibrillation (closed circles) and 26 of short-term fibrillation (open circles) is shown. The majority of values lies above the dotted line which is the absolute upper limit of normal.

infarction developed atrial fibrillation. In 3 of these 4, there was infarction of muscle in the interatrial septum, in 2 of the 4 the coronary thrombosis lay proximal to the origin of the nodal artery, yet none of the 4 cases showed infarction within the node itself. A single example of atrial fibrillation complicating high intracranial pressure was encountered and no cardiac lesion was demonstrable.

Long-term fibrillation The main pathological conditions present in the 74 cases with established atrial fibrillation are shown in Table 2. In many instances left and right atrial volumes are high (Fig. I and 2), the largest atria being found in cases due to chronic rheumatic mitral valve disease. Severe damage to the SA node (Fig. 3) is present in some cases and no muscle fibres may be found within the node, a finding particularly characteristic of chronic rheumatic cases. Fibrous thickening and obliteration of 
TABLE 2 Essential pathology in long-term ( $>$ I month) atrial fibrillation

\begin{tabular}{|c|c|}
\hline Cor pulmonale & I0 \\
\hline Chronic rheumatic valve disease & 18 \\
\hline Ischaemic heart disease with LV failure & 25 \\
\hline Hypertension with LV failure & 7 \\
\hline Secondary carcinoma & 4 \\
\hline Lone 'senile' fibrillation & 6 \\
\hline Cardiomyopathy & 2 \\
\hline Ebstein's anomaly & $\mathbf{I}$ \\
\hline Asymmetric hypertrophy & $\mathbf{I}$ \\
\hline Total & 74 \\
\hline
\end{tabular}

the pericardial sac is also particularly associated with severe degrees of damage to the SA node. Other cases show a diminution of muscle content for age, while a minority has morphologically normal nodes.

The internodal tracts show corresponding degrees of muscle loss reflected as an increase in fibrosis (Fig. 4), but as with the SA node examples are encountered with normal internodal tracts. The muscle loss within the node and internodal tracts has no specific features; even in cases with rheumatic valve disease there was no evidence of active inflammation and no Aschoff bodies were seen.

Nine of the patients with long-term fibrillation had stenosis or occlusion of the arterial supply to the SA node; in 5 cases this was the only morphological abnormality seen in the atria.

Four patients had secondary carcinoma involving the heart; in 2 the tumour had invaded the left atrium diffusely but did not encroach on the internodal tracts; one patient had invasion of the right atrium with total destruction of the SA node, while one had focal deposits throughout the atrial muscle including the internodal tracts.

An analysis of the combinations of morphological lesions in the atria in chronic atrial fibrillation is shown in Table 3.

Thrombosis in the left atrial appendage was found in 46 patients with long-term fibrillation, and in 19, cerebral infarction, presumably due to emboli, was present. Only 3 of the 19 patients with short-term fibrillation had left atrial thrombus and one had cerebral infarction (Table 4).

\section{Discussion}

In this series the development of terminal atrial fibrillation was associated in half the cases with acute pericarditis and this association is well recognized clinically (Stock, 1970). The sinoatrial node lies immediately adjacent to the pericardium and is therefore very liable to be involved in an inflammatory process.

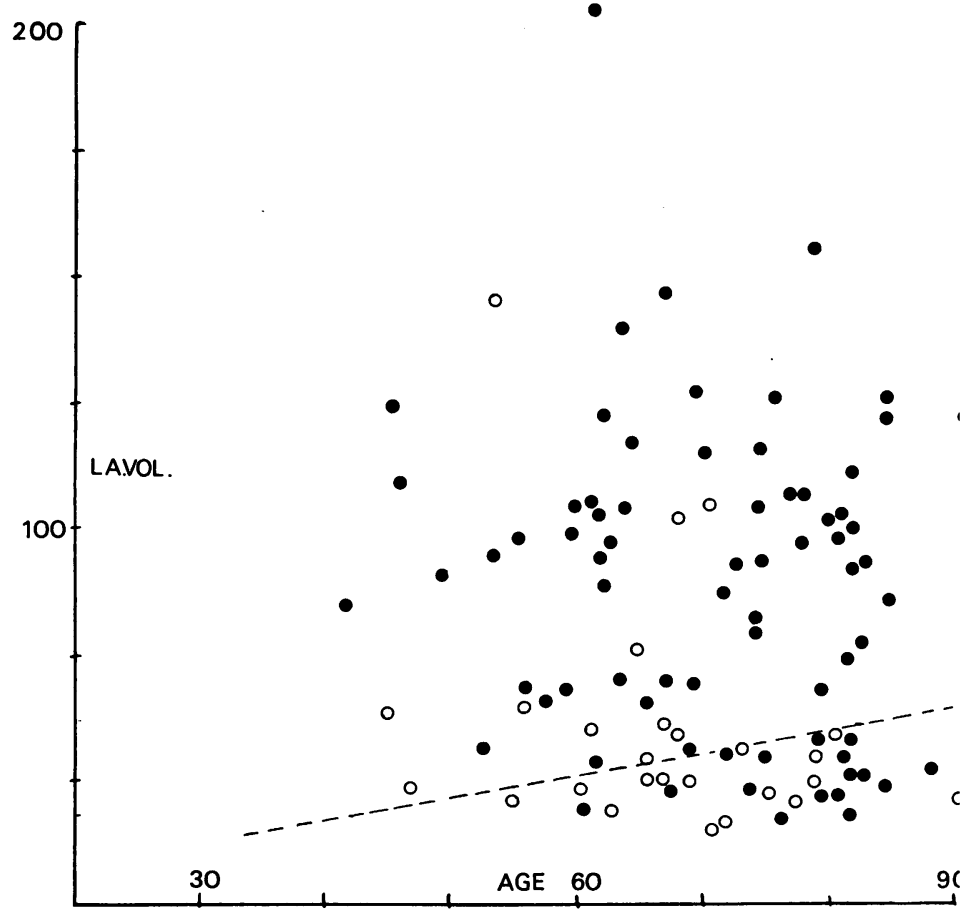

FIG. 2 The left atrial volume is plotted against age in 74 cases of long-term fibrillation (closed circles) and 26 of short-term fibrillation (open circles). The dotted line is the absolute upper limit of normal.

Clinicians are aware that atrial fibrillation may be a feature of massive pulmonary embolism (Stock, 1970). In the present series the only cardiac abnormality found in such cases was a high right atrial volume: the presumption could be made that the acute distension of atrium with sudden stretching of the atrial muscle precipitated the arrhythmia.

TABLE 3 Atrial lesions found in long-term fibrillation

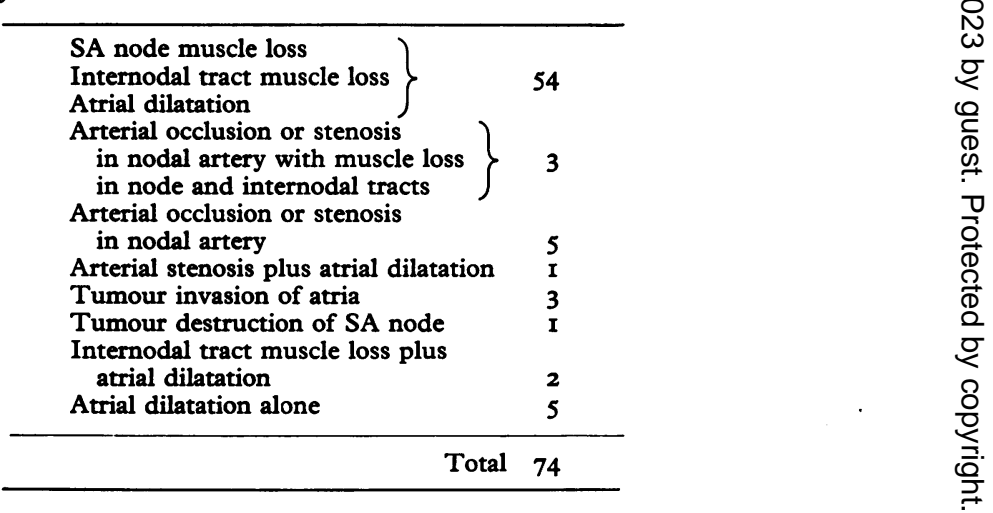


TABLE 4 Atrial fibrillation: 100 cases

\begin{tabular}{lccc}
\hline & & $\begin{array}{c}\text { Thrombus } \\
\text { in atria }\end{array}$ & $\begin{array}{l}\text { Cerebral } \\
\text { emboli }\end{array}$ \\
\hline Short-term fibrillation & 26 & 3 & I \\
Long-term fibrillation & 74 & 46 & 19 \\
\hline
\end{tabular}

Atrial fibrillation complicating acute myocardial infarction clearly has a multifactorial $\Delta$ basis as previously stressed by James (I962).

The putative lesions include acute pericar, ditis, infarction of the internodal tracts, infarction or haemorrhage in the node itself and occlusion of the nodal artery. Cushing and his colleagues (1942) had previously emphasized the strong association between atrial infarction and atrial fibrillation. Sinus arrest as a complication of nodal artery occlusion is also well documented (Lippestad and Marton, 1967). It is significant that the patients with short-term fibrillation were elderly, the youngest being 72 years of age at death, since we have already suggested that precipitation of acute atrial fibrillation may be aided by natural ageing changes in the atria (Davies and Pomerance, 1972). Burch and DePasquale (1969) have arrived at similar conclusions based on clinical experience.

The pathological basis of chronic atrial fibrillation has been a matter of some contention, though the preponderance of rheu-

$=$ matic valve disease, ischaemic hypertensive heart disease, and cor pulmonale is well tdocumented (Corazza and Pastor, 1958; Marriot and Myerburg, 1970). The present study suggests that several morphological . changes are found, often in a variety of combinations. Probably the most significant

- change is loss of nodal muscle, and it is obvious that where no muscle remains sinus

$\checkmark$ rhythm is not possible. Many cases do, however, have subtotal damage to the node which "correlates well with the clinical observation that sinus rhythm may often be temporarily restored by DC conversion, even after some years of atrial fibrillation (Waris et al., I97I). It is also apparent from the present study that - stenosis of the nodal arterial supply may in itself be associated with atrial fibrillation even though there is no obvious lesion of the node and internodal tracts. Support for this finding comes from similar individual cases described by Lippestad and Marton (1967) and Cancilla and Nicklaus (1966). Of the 5 patients with nodal artery stenosis without other morphological abnormality within the atria, 2 had preceding sinus bradycardia and sinoatrial arrest. Ligation of the nodal artery in the dog

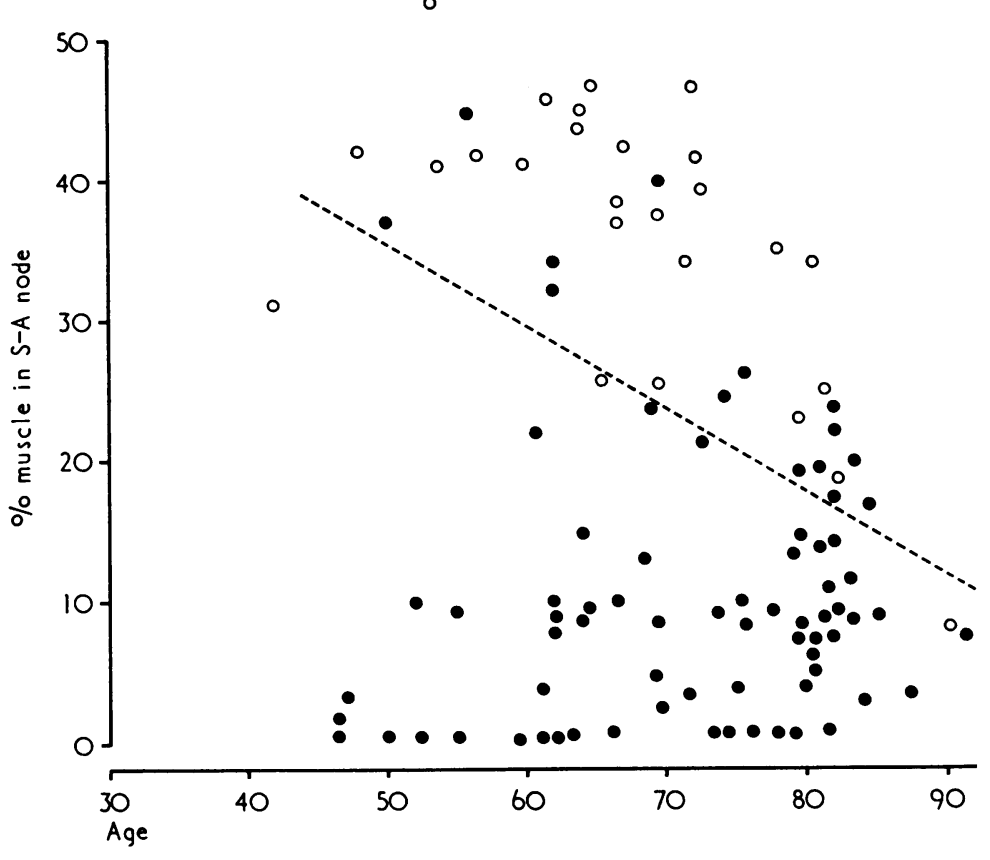

FIG. 3 The per cent amount of muscle present in the $S A$ node is plotted against age in long-term fibrillation (closed circles) and short-term fibrillation (open circles). The dotted line is the absolute lower limit of normal. The majority of cases with long-term fibrillation fall below the normal limit, many having no muscle present. The majority of cases with short-term fibrillation are within the normal range (above dotted line).

will produce atrial arrhythmias, including sinus arrest and atrial fibrillation (James and Hershey, 1962).

Muscle loss within the SA node of patients with atrial fibrillation has been noted by Hudson (1960), Hildebrand (1964), and Rossi (1969). Rossi has also stressed that there is concomitant destruction of nerve endings within the node. The muscle loss within the node and internodal tracts has no specific features to suggest its pathogenesis; no inflammatory cells were seen, though in cases of rheumatic valve disease a previous myocarditis cannot be excluded. While ischaemic changes may be responsible in many cases, in some where this might be suspected or presumed there were no significant lesions of either the major coronary arteries or the interatrial vessels. Fibrous thickening of the pericardium is associated with obvious nodal damage, suggesting that organization of pericarditis may be a factor in some instances. 
Clinical studies also indicate a close association between Pick's disease and atrial fibrillation (Dalton, Pearson, and White, 1956; Fowler, 1970). Atrial dilatation commonly accompanies chronic atrial fibrillation (Laas, 1962) but this is not inevitable (Fig. I and 2). Larger atria were associated with thrombosis within the appendage, and death due to cerebral emboli was common. Large atria are associated with a tendency to atrial fibrillation (Moore et al., 1960, 1965) in experimental conditions, but in man atrial fibrillation is usually taken to be the cause of atrial dilatation.

While it is conventional to regard the fibrotic changes in the node and atria as the cause of atrial fibrillation, it is also possible that they result from the arrhythmia and consequent disordered function of the chamber. Some support for this view comes from the rough correlation between the degree of atrial damage and duration of atrial fibrillation. The similarity of the changes found in the atria in a wide range of cardiac conditions may also support this view. The number of permanently successful DC versions certainly falls the longer atrial fibrillation has been present (Waris et al., 197I ; Szekely, Sideris, and Batson, 1970). There remain some cases which have atrial dilatation alone or associated only with some internodal tract fibrosis. All such cases were elderly, over 80 years of age, and had SA nodes lying at the extreme lower limit of the normal morphological range; no other cardiac abnormality could be found. All had some deposits of amyloid in the left atrium though these did not encroach on the node or internodal tracts. Such cases represent a 'senile' lone atrial fibrillation, the exact cause for which is obscure but which is clearly recognized by clinicians (Burch and DePasquale, 1969). The series is biased towards geriatric patients, and the incidence of atrial fibrillation complicating ischaemic and hypertensive heart disease (Table 2) is certainly higher than that reported in many clinical series. There thus appears to be an association in this series between old age, cardiac failure, and atrial fibrillation, and there is some support for the view (Marriot and Myerburg, 1970) that episodes of cardiac failure may initiate atrial fibrillation in the aged.

Atrial fibrillation is a well-known clinical complication of involvement of the heart by secondary carcinoma. In the series overall malignancy was responsible for II cases. The actual mechanism may be pericarditis, atrial invasion, or actual destruction of the node or internodal tracts. No example of invasion of

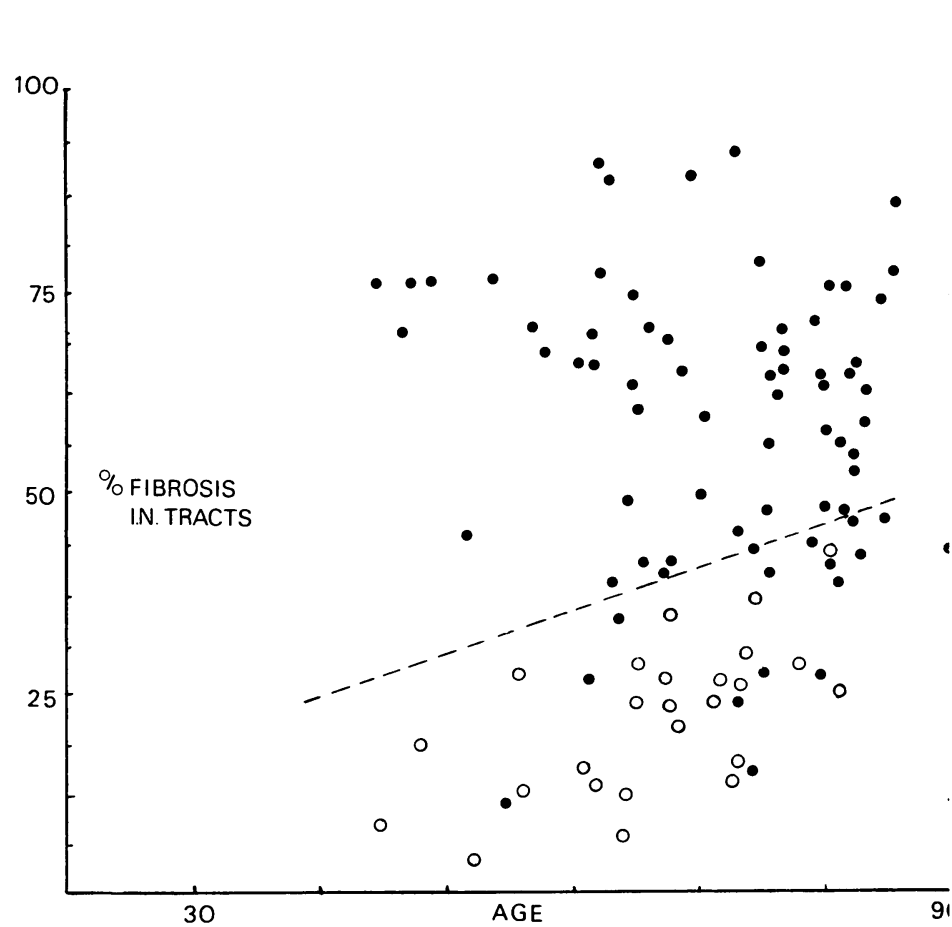

FIG. 4 The percentage of fibrous tissue within the internodal tracts is plotted against age. The majority of long-term fibrillation cases (closed circles) is above the limit of normal (dotted line), while the short-term fibrillation cases (open circles) lie within the normal limit.

the vagi alone has been encountered, though such cases have been published (Davies, 1957). In common with other series (Pearson, 1948) carcinoma of the bronchus predominated, being found in 9 of II cases.

\section{References}

Burch, G. E., and DePasquale, N. D. (1969). Geriatric cardiology. American Heart fournal, 78, 700.

Cancilla, P. A., and Nicklaus, T. M. (I966). Atrial fibrillation with occlusion of the sinus node artery. Archives of Internal Medicine, 117, 422.

Corazza, L. J., and Pastor, B. H. (1958). Cardiac arrhythmias in chronic cor pulmonale. New England fournal of Medicine, 259, 862.

Cushing, E. H., Feil, H. S., Stanton, E. J., and Wartman, W. B. (1942). Infarction of the cardiac auricles (atria): clinical, pathological, and experimental studies. British Heart fournal, 4, 17.

Dalton, J. C., Pearson, R. J., and White, P. D. (1956). Constrictive pericarditis: a review and long-term follow-up of 78 cases. Annals of Internal Medicine, 45,445 .

Davies, M. J., and Pomerance, A. (1972). Quantitative study of ageing changes in the human sinoatrial node and internodal tracts. British Heart fournal, 34, 150 . 
Davies, P. (1957). Sino-auricular block associated with intrathoracic new growths. British Heart fournal, 19, 431 .

Dunnill, M. S. (1962). Quantitative methods in the study of pulmonary pathology. Thorax, 17, 320 .

- Fowler, N. O. (1970). Diseases of the pericardium. In The Heart, and ed., p. 1254. Ed. by J. W. Hurst and R. B. Logue. McGraw-Hill, New York.

Hildebrand, H. E. (1964). Der Sinusknoten bei Arrhythmie. Virchows Archiv für pathologische Anatomie und Physiologie und für Klinische Medizin, 337, 515 .

Hoffman, B. F., and Cranefield, P. F. (1960). Electrophysiology of the Heart. McGraw-Hill, New York.

t Hudson, R. E. B. (1960). The human pacemaker and its pathology. British Heart fournal, 22, 153.

Hudson, R. E. B. (1965). Cardiovascular Pathology. Edward Arnold, London.

James, T. N. (196I). Morphology of the human atrioventricular node with remarks pertinent to its electrophysiology. American Heart fournal, 62, 756.

James, T. N. (1962). Arrhythmias and conduction disturbances in acute myocardial infarction. American Heart fournal, 64, 4I6.

James, T. N. (1963). The connecting pathways between the sinus node and A-V node and between the right and the left atrium in the human heart. American Heart fournal, 66, 498.

James, T. N., and Hershey, E. A. (1962). Experimental studies on the pathogenesis of atrial arrhythmias in myocardial infarction. American Heart fournal, 63 , 196.

- Laas, E. (1962). Das Arrythmieherz. Zentralblatt für allgemeine Pathologie und pathologische Anatomie, 103, 552.

Lippestad, C. T., and Marton, P. F. (1967). Sinus arrest in proximal right coronary artery occlusion. American Heart Fournal, 74, 55I.

Marriot, H. J. L., and Myerburg, R. J. (1970). Recog- nition and treatment of cardiac arrhythmias and conduction disturbances. In The Heart, and ed., p. 489. Ed. by J. W. Hurst and R. B. Logue. McGraw-Hill, New York.

Moore, E. N., Fisher, G., Detweiler, D. K., and Moe, G. K. (1960). The initiation and maintenance of atrial fibrillation in normal young and adult cattle. Physiologist, 3, I16.

Moore, E. N., Fisher, G., Detweiler, D. K., and Moe, G. K. (1965). The importance of atrial mass in the persistance of atrial fibrillation. In Proceedings International Symposium on Comparative Medicine. Ed. by R. J. Tashjian. Eaton Laboratory, Montreal.

Pearson, J. E. (1948). Myocardial metastasis of bronchial carcinoma and other neoplasms. British fournal of Tuberculosis and Diseases of the Chest, 42, 31.

Rossi, L. (1969). Histopathologic Features of Cardiac Arrhythmias. Casa editrice Ambrosiana, Milan.

Stock, J. P. P. (1970). Diagnosis and Treatment of Cardiac Arrhythmias, 2nd ed. Butterworth, London.

Szekely, P., Sideris, D. A., and Batson, G. A. (1970). Maintenance of sinus rhythm after atrial defibrillation. British Heart Fournal, 32, 741.

Taran, L. M., and Szilagyi, N. (1958). Electrocardiographic changes with advancing age. Geriatrics, 13, 352.

Vassalle, M., Greenspan, K., Jomain, S., and Hoffman, B. F. (I964). Effects of potassium on automaticity and conduction of canine hearts. American fournal of Physiology, 207, 334.

Waris, E., Kreus, K. E., and Salokannel, J. (197I). Factors influencing persistence of sinus rhythm after DC shock treatment of atrial fibrillation. Acta Medica Scandinavica, 189, I6r.

Requests for reprints to Dr. M. J. Davies, St. George's Hospital Medical School, London SWI. 